\title{
SIZE-DEPENDENT POPULATION DYNAMICS OF MICROTUS OCHROGASTER
}

Lefkovitch (1965a) generalized Leslie's (1945) matrix model of age-structured population growth to include stage-transition matrices of the form

$$
\left[\begin{array}{llll}
f_{1}+p_{11} & f_{2}+p_{12} & \ldots & f_{n}+p_{1 n} \\
p_{21} & p_{22} & \ldots & p_{2 n} \\
\ldots & \ldots & \ldots & \ldots \\
\cdots & \ldots & \ldots & \ldots \\
p_{n 1} & p_{n 2} & \ldots & p_{n n}
\end{array}\right]
$$

where $f_{i}$ is the fecundity of organisms in stage $i$, and $p_{i j}$ is the probability that an organism in stage $j$ will enter stage $i$ in the next time period. When post-multiplied by a vector whose elements represent the number of organisms in each stage at time $t$, the product is a vector of the number of organisms in each stage at time $t+1$.

Invertebrate biologists (Lefkovitch 1965b; Hughes 1984) and botanists (Bosch 1971; Caswell and Werner 1978) have used stage-transition matrices to analyze population dynamics in discrete time, but vertebrate biologists have not, perhaps because of the lack of reliable "stages" into which animals with distinct rates of fecundity and survival can be grouped. Age remains the usual state variable in demographic studies of vertebrates. However, as demonstrated by actuarial use of concomitant variables such as sex, geographic location, body mass, and other physical characteristics in survival analysis (Elandt-Johnson and Johnson 1980) and by the use of body size in a population-size estimation of whales (Allen 1980), many possible stage categories are useful in an analysis of vertebrate population dynamics. Well-established methodologies exist for stable-population analysis of both stage-transition (Lefkovitch) matrices (Vandemeer 1975; Hughes 1984) and hybrid age-stage-transition matrices (Law 1983); sensitivity analyses (Caswell 1978) can be used to provide information about the sensitivity of the dominant eigenvalue (rate of population growth) to small changes in elements of the transition matrix. Using stages other than age in vertebrate populations can increase the accuracy of population projections and provide new insights into the evolution of life history characteristics. Furthermore, body mass or other measures of size can be used when age cannot be accurately determined. Such is the case with our study population of prairie voles (Microtus ochrogaster).

In addition to being much easier to measure, size may be preferable to age for

Am. Nat. 1986. Vol. 127, pp. 902-908.

(C) 1986 by The University of Chicago. 0003-0147/86/2706-0012\$02.00. All rights reserved. 
other reasons. Many free-living animals (i.e., most rodents) do not live long enough for changes in fecundity and survival resulting from senescence to be expressed (Krebs et al. 1969; Sauer and Slade 1985). In these animals, body mass reflects their current physiological condition and may be a more useful state variable than age. Evidence exists that fecundity and survival vary more predictably as a function of body mass than of age in many species of rodents (Fitch 1957; Rose and Gaines 1978; Myers and Master 1983). In addition, demographic models based on body mass can tie together the demography (on which life history theoreticians base their models) and the physiology of the animals. It is possible that the cost of reproduction is expressed through a loss in body mass by parents, which is not immediately reflected in survival.

Relationships between population dynamics and somatic growth of individuals cannot be examined using age-based demographic models. We modeled the population dynamics of the cotton rat (Sigmodon hispidus) using body-mass classes as stage categories in Lefkovitch matrices, and we found that the population growth rate was most sensitive to rapid growth by light animals in the summer and to their increased survival in the winter (Sauer and Slade 1985). A comparison of growth rates of small cotton rats from Kansas and Texas showed that Kansas cotton rats grew much more rapidly, a result that conforms to the predictions of the sensitivity analysis. However, that study combined data from several years, and a prediction of actual population dynamics over short time intervals was not completely successful. In this paper we use body-mass categories to analyze the monthly population dynamics of prairie voles at the Nelson Environmental Study Area $17 \mathrm{~km}$ northeast of Lawrence, Kansas. We know of no other investigators who have applied these techniques to the analysis of a mammalian population; this paper thus presents a unique demonstration of an accurate month-specific prediction of population dynamics using mass-based transition matrices.

\section{METHODS}

The prairie vole population has been livetrapped during 3-day trapping sessions on a 100-station grid with two live traps per station at least monthly since 1974 . Body masses were recorded at first capture within a trapping session for all animals, and animals were permanently marked by toe-clipping. We derived transition probabilities between mass classes of female voles for each month. Five mass classes were used in the analysis: mass class 1 was 1-20 g; mass class 2, 21$30 \mathrm{~g} ; . .$. ; mass class $5,>50 \mathrm{~g}$. Growth rates were found by dividing the change in mass of a marked animal between two trapping periods by the number of weeks between the two captures. These were stored by month and mass class at the first capture. A transition was then estimated by multiplying the growth rate by 4 wk and adding this to the initial mass in order to find the mass class into which the animal moved. These transitions provide results similar to those obtained from using the observed transitions from one trapping period to another. Since trapping was not always conducted at exactly 30-day intervals (the mean period of time between two captures used for a growth rate was 36.5 days), we used a linear adjustment to standardize the time periods between captures. The $p_{i j}$ were defined 
as the number making transitions from any mass class $j$ to mass class $i$ divided by the total number of animals observed in mass class $j$. These proportions were standardized to sum to the survival rate of females for that month, which was estimated from the livetrapping data using the Jolly-Seber method (Seber 1973). Dispersal is confounded with death in these survival estimates.

Mass-specific fecundity was calculated as the product of litter size, proportion of reproductive females in each mass class, sex ratio, and monthly survival of the mother. These components of fecundity were estimated using our data and those of other investigators who studied prairie voles near Lawrence. Rose and Gaines (1978) provided bimonthly estimates of litter sizes; hence, our estimates of litter size did not change from year to year. The proportion of reproductively active females and the survival rates were estimated monthly from our field data, and a $1: 1$ sex ratio at birth was assumed. Prairie voles have a gestation period of about 21 days (Bee et al. 1981), and the transition matrices have a period of 30 days; hence, fecundity elements were adjusted for the survival of the young from birth until they began to leave the nest, but only through the mother's survival, since we could not estimate perinatal survival of young.

We estimated Lefkovitch transition matrices based on mass for $43 \mathrm{mo}$, grouped in four series of successive months. Sample sizes of voles in other months were too small to allow an estimation of transition probabilities. In the analyzed months, the mean sample size of voles used in estimating transition probabilities was 25 . In addition, 7 of the 43 estimated transition matrices were unstable and were not considered in the eigenvalue analysis. Assuming a stable mass distribution, an analysis of the eigenstructure of these matrices provides information about the finite rate of increase of the population (the dominant eigenvalue), the stable mass-distribution and mass-specific reproductive values (left and right eigenvectors corresponding to the dominant eigenvalue, respectively), and the sensitivity of the finite rate of increase to mass-specific changes in growth and fecundity.

\section{RESULTS AND DISCUSSION}

The dominant eigenvalues of the stable transition matrices were quite variable over the months of the study (0.31-1.34). We compared mean eigenvalues for each month to determine if seasonal differences occurred in population growth (table 1). No seasonal variation could be found $(F=2.02$; $\mathrm{df}=11,24 ; P>0.1)$. There was also no distinct year-to-year variation in the eigenvalues $(F=2.24$; $\mathrm{df}$ $=6,29 ; P>0.1$ ).

The structure of the transition matrices varied from month to month, but all of the matrices conformed to the same general pattern, which the October 1981 transition matrix (table 2) typifies. Reproduction was mass-specific with no reproduction in mass class 1 and a general increase in the proportion reproducing as the mass increased in classes 2-5. This pattern is reflected in the first row of the matrix. Stable mass distributions of the transition matrices had a consistent pattern, with most animals in the lightest mass class and smaller proportions of animals in heavier mass classes. Reproductive value increased with mass class. A 
TABLE 1

Mean Monthly Dominant Eigenvalues (population growth rates) of Transition Matrices from a Microtus ochrogaster Population, with Associated Sample Sizes

\begin{tabular}{lcc|ccc}
\hline \hline Month & $\begin{array}{c}\text { Mean } \\
\text { Eigenvalue }\end{array}$ & $N$ & Month & Mean & EigenValue \\
\hline Jan & 1.081 & 1 & Jul & 1.107 & $N$ \\
Feb & 1.198 & 3 & Aug & 1.074 & 3 \\
Mar & 0.995 & 3 & Sep & 1.299 & 3 \\
Apr & 1.190 & 4 & Oct & 1.122 & 3 \\
May & 0.854 & 4 & Nov & 1.166 & 2 \\
Jun & 0.822 & 5 & Dec & 0.742 & 2 \\
\hline
\end{tabular}

TABLE 2

October i98i Transition Matrix from a Microtus ochrogaster Population, with Associated Sensitivity Matrix, Stable Mass Distribution, and Reproductive Values

\begin{tabular}{|c|c|c|c|c|c|c|}
\hline \multirow{2}{*}{$\begin{array}{l}\text { MASS ClaAs } \\
\text { IN October }\end{array}$} & \multicolumn{5}{|c|}{ Mass Class in November } & \\
\hline & 1 & 2 & 3 & 4 & 5 & \\
\hline & \multicolumn{5}{|c|}{ TRANSITION MATRIX } & $\begin{array}{l}\text { STABLE MASS } \\
\text { DISTRIBUTION }\end{array}$ \\
\hline 1 & .17 & .13 & .81 & 1.44 & 1.61 & .4108 \\
\hline 2 & .34 & .34 & 0 & 0 & 0 & .1419 \\
\hline 3 & .34 & .51 & .64 & $\mathbf{0}$ & 0 & .3092 \\
\hline 4 & 0 & 0 & .21 & 0.53 & 0.71 & .1092 \\
\hline \multirow[t]{3}{*}{5} & 0 & 0 & 0 & 0.32 & 0.14 & .0294 \\
\hline & & & & & & REPRODUCTIVE \\
\hline & \multicolumn{5}{|c|}{ SENSITIVITY MATRIX } & VALUES \\
\hline 1 & .24 & .08 & .18 & .06 & .02 & 1.0000 \\
\hline 2 & .20 & .11 & .23 & .08 & .02 & 1.2488 \\
\hline 3 & .52 & .18 & .39 & .18 & .04 & 2.1451 \\
\hline 4 & .76 & .26 & .57 & .20 & .06 & 3.1273 \\
\hline 5 & .78 & .27 & .54 & .21 & .06 & 3.2404 \\
\hline
\end{tabular}

NoTE.-Transition probabilities were determined using growth data from 32 prairie voles; the dominant eigenvalue is $\mathbf{1 . 3 2}$.

sensitivity analysis of the matrices (Caswell 1978) indicated a general pattern in which the population growth rate was most sensitive to the increased growth and survival of lighter animals, suggesting that adaptations to increase survival and growth rates of these light animals would most increase the finite rate of increase at any time of year. Because fecundity increased with body mass, more-rapid somatic growth would result in increased rates of maturation.

The eigenvalue analysis depends on two assumptions about the population: the Lefkovitch matrix adequately describes the dynamics of the population, and the population has attained a stable mass distribution. Many of the difficulties associated with the analysis of transition matrices result from the use of a single matrix to project over many generations (Mendelssohn 1976). We argue that, over a single generation, the use of time-specific data can provide an accurate view of the 
dynamics of the population. The only composite elements, as opposed to timespecific elements, of our transition matrices are the estimates of litter size, which could not be derived from our field data. Determining whether the mass distribution of a population is stable is, at present, an unsolved problem for small-mammal ecologists. Biases in the livetrapping procedure (Beacham and Krebs 1980) make it unlikely that the numbe $s$ of animals in each mass class are equally sampled. The only way that this bias enters our analysis, however, is through the decreased sample sizes of light animals. The somatic growth rates should not be biased by the trapping procedure.

These transition matrices provide an accurate model of the changes in prairie vole numbers over time. To show this, we projected the female population in each of the time series of continuous data, starting with the observed mass structure of the first month in the period and projecting with the month-specific transition matrices, and we plotted these against estimates of population density (fig. 1). Population size was estimated using both the Jolly-Seber method (Seber 1973) and the method of minimum number known alive. Both estimators of population size provided similar results; however, the minimum number known alive more closely fit the March-November 1978 series, and the Jolly-Seber estimates better fit September-December 1982. Since the minimum number known alive tends to underestimate population size (Nichols and Pollock 1983), we present the JollySeber estimates. Because any error in the projections is cumulative and the population size during any month may vary through immigration and stochastic effects, the agreement between observed and expected values is reasonable. In two of the series, a single month caused the projections to vary, but "restarting" the projections after these months using the observed mass structure of the next month caused projected values to follow the observed values more closely. Although a posteriori modeling of population dynamics is less desirable than verification of the model against an independent data set, these results do show that the model fits the observed population dynamics. At least on a month-tomonth basis, the simple matrix model gave an adequate description of the population dynamics, even though we assumed negligible immigration and year-invariant litter sizes.

As stated earlier, we could not determine the ages of animals in our population, and we therefore could make no direct comparison of age- and mass-based methods (such as the analysis in Werner and Caswell 1977 of a population of teasel, Dipsacus sylvestris Huds.). Subsequent to our analysis of voles, we compared age- and mass-based demography in another small mammal, the Uinta ground squirrel (Spermophilus armatus), and we found that mass- and age-based analyses provided similar results. However, data concerning body mass were much easier to collect than age data (Sauer and Slade 1986).

Mass-based demography provides a means of analyzing the dynamics of smallmammal populations when the animals cannot be aged accurately, but the effectiveness of the method depends on the degree to which survival and fecundity for the population are determined by body mass. Voles are good potential subjects for this form of population analysis, since seasonal variation in somatic growth rates makes body mass a poor indicator of age (Brown 1973). The validity of massbased demography remains to be determined for other species of mammals. 


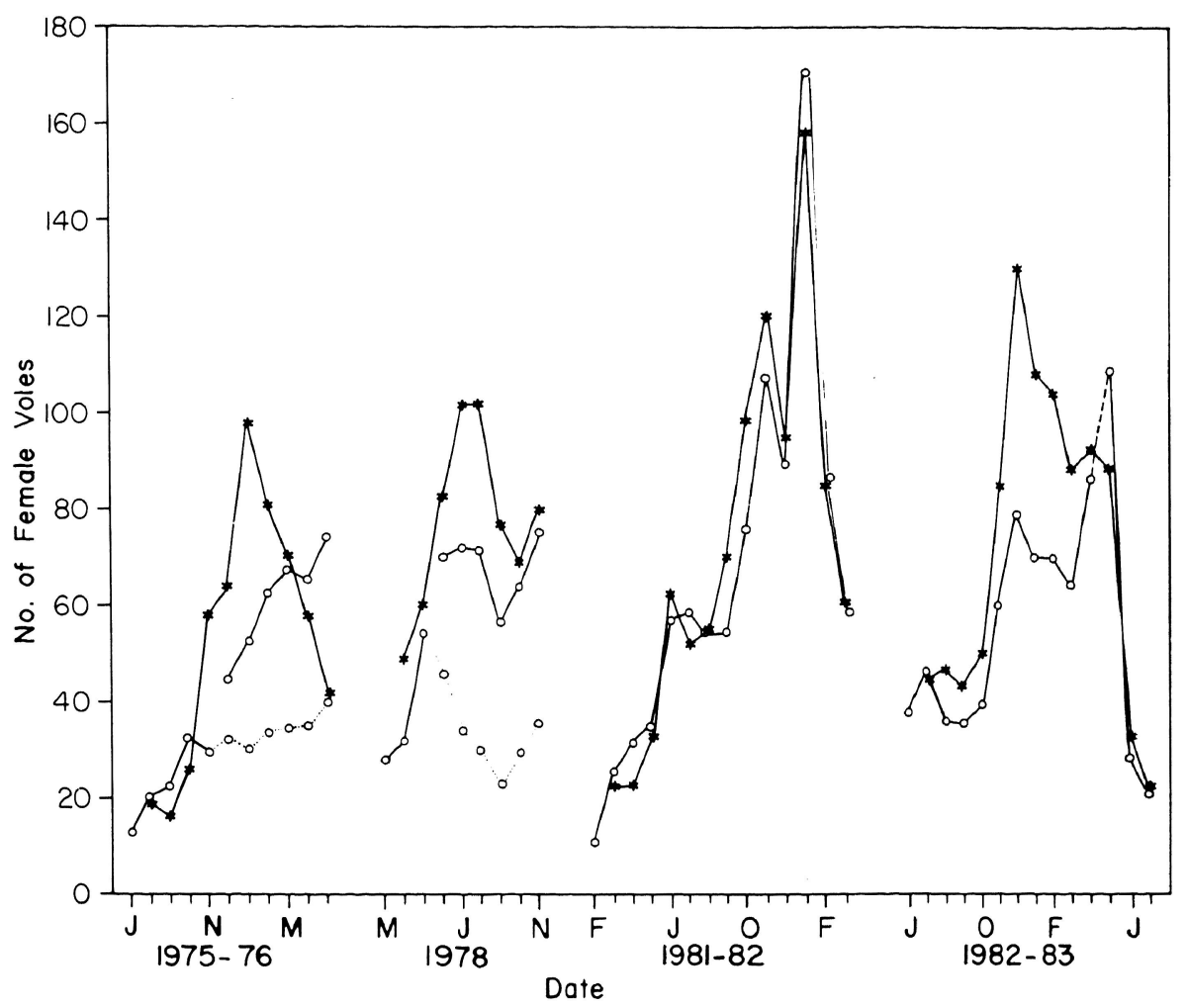

FIG. 1.-Population sizes of prairie voles through time: asterisks, observed; open circles, expected. Expected values are projected from observed numbers of voles in the first month of a series using the appropriate transition matrices. Dashed line, a missing month (April 1983) projected using the last available month (March 1983); dotted lines, the continuation of projections that were restarted (see the text for details).

However, our results indicate that the relative importance of age and mass in determining survival and fecundity should be assessed in mammalian life history studies. In fact, body mass is often measured in studies of mammalian population dynamics, even when the primary emphasis of the study is age-based population characteristics, and a reanalysis of these data from a mass-based perspective could provide new insights into mammalian life histories.

\section{ACKNOWLEDGMENTS}

We thank R. K. Swihart, G. E. Glass, J. K. Armstrong, J. H. Honacki, B. A. Carnes, H. Levenson, and L. R. McClenaghan for assistance with the fieldwork. R. S. Hoffmann, R. D. Holt, R. F. Johnston, and R. K. Swihart commented on the manuscript. We were supported by University of Kansas General Research Fund grants 3349-5038, 3093-5038, 3534-0038, and 3509-0038 (N.A.S.) and by a Graduate Honors Fellowship (J.R.S.).

LITERATURE CITED

Allen, K. R. 1980. Conservation and management of whales. Butterworths, London.

Beacham, T. D., and C. J. Krebs. 1980. Pitfall versus live-trap enumeration of fluctuating populations of Microtus townsendii. J. Mammal. 61:486-499. 
Bee, J. W., G. E. Glass, R. S. Hoffmann, and R. R. Patterson. 1981. Mammals in Kansas. Univ. Kans. Publ., Publ. Education Ser. 7:1-300.

Bosch, C. A. 1971. Redwoods: a population model. Science (Wash., D.C.) 172:345-349.

Brown, E. B., III. 1973. Changes in patterns of seasonal growth of Microtus pennsylvanicus. Ecology 54:1103-1110.

Caswell, H. 1978. A general formula for the sensitivity of population growth rate to changes in life history parameters. Theor. Popul. Biol. 14:215-230.

Caswell, H., and P. A. Werner. 1978. Transient behavior and life history analysis of teasel (Dipsacus sylvestris Huds.). Ecology 59:53-66.

Elandt-Johnson, R. C., and N. L. Johnson. 1980. Survival models and data analysis. Wiley, New York.

Fitch, H. S. 1957. Aspects of reproduction and development in the prairie vole (Microtus ochrogaster). Univ. Kans. Publ. Mus. Nat. Hist. 10:129-161.

Hughes, T. P. 1984. Population dynamics based on individual size rather than age: a general model with a reef coral example. Am. Nat. 123:778-795.

Krebs, C. J., B. L. Keller, and R. H. Tamarin. 1969. Microtus population biology: demographic changes in fluctuating populations of $M$. ochrogaster and $M$. pennsylvanicus in southern Indiana. Ecology 50:587-607.

Law, R. 1983. A model for the dynamics of a plant population containing individuals classified by age and size. Ecology 64:224-230.

Lefkovitch, L. P. 1965a. The study of population growth in organisms grouped by stages. Biometrics 21:1-18.

- 1965b. The effects of adult emigration on populations of Lasioderma serricorne. Oikos 15:200 210.

Leslie, P. H. 1945. The use of matrices in certain population mathematics. Biometrika 33:183-212.

Mendelssohn, R. 1976. Optimization problems associated with a Leslie matrix. Am. Nat. 110:339-349.

Myers, P., and L. L. Master. 1983. Reproduction by Peromyscus maniculatus: size and compromise. J. Mammal. 64:1-18.

Nichols, J. D., and K. H. Pollock. 1983. Estimation methodology in contemporary small-mammal capture-recapture studies. J. Mammal. 64:253-260.

Rose, R. K., and M. S. Gaines. 1978. The reproductive cycle of Microtus ochrogaster in eastern Kansas. Ecol. Monogr. 48:21-42.

Sauer, J. R., and N. A. Slade. 1985. Mass-based demography of a hispid cotton rat (Sigmodon hispidus) population. J. Mammal. 66:316 328.

1986. Uinta ground squirrel demography: is body mass a better categorical variable than age? Ecology (in press).

Seber, G. A. F. 1973. The estimation of animal abundance and related parameters. Griffin, London.

Vandemeer, J. H. 1975. On the construction of the population projection matrix for a population grouped in unequal stages. Biometrics 31:239-242.

Werner, P. A., and H. Caswell. 1977. Population growth rates and age versus stage-distribution models for teasel (Dipsacus sylvestris Huds.). Ecology 58:1103-1111.

\section{Department of Systematics and ECOLOGY and Museum of Natural History The UNIVERSITY OF Kansas LAWRENCE, KanSAS 66045 Submitted June 14, 1985; Revised September 20, 1985; Accepted December 9, 1985}

\footnotetext{
* Present address: U.S. Fish and Wildlife Service, Office of Migratory Bird Management, Patuxent Wildlife Research Center, Laurel, Maryland 20708.
} 